\title{
DIFFERENTIAL EVOLUTION ALGORITHM APPLIED IN A NUMERICAL COST OPTIMIZATION DESIGN OF A SHELL AND-TUBE HEAT EXCHANGER
}

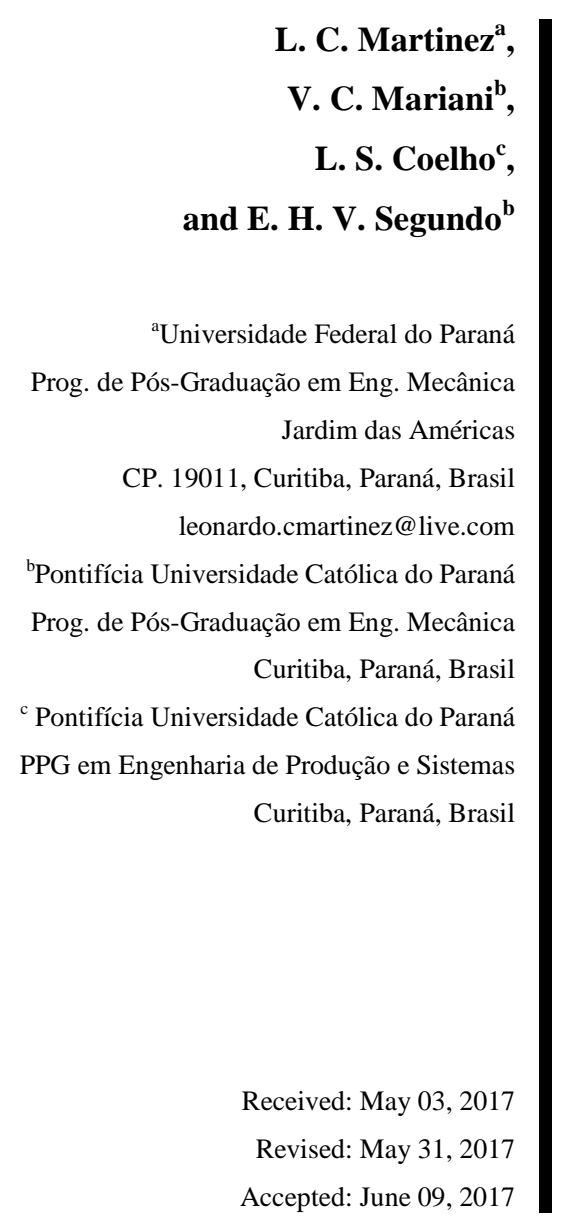

NOMENCLATURE

$\mathrm{a}_{1} \quad$ Numeric Constant

$\mathrm{a}_{2} \quad$ Numeric Constant

$\mathrm{a}_{3} \quad$ Numeric Constant

A Sup. Area of Heat Exchanger

$\mathrm{A}_{\mathrm{s}} \quad$ Shell Passing Area

B Deflectors Spacing

C Numeric Constant

$\mathrm{C}_{\mathrm{e}} \quad$ Energy Cost

$\mathrm{C}_{\mathrm{i}} \quad$ Investment Capital

$\mathrm{C}_{\mathrm{o}} \quad$ Annual Operation Cost

$\mathrm{C}_{\text {od }}$ Depreciation Cost

$\mathrm{c}_{\mathrm{p}} \quad$ Specific Heat

$\mathrm{C}_{\text {tot }}$ Total Cost

$d_{e} \quad$ Eq. Diameter of Shell Side

$d_{i} \quad$ Internal Diameter of Tube

$\mathrm{d}_{\mathrm{o}} \quad$ External Diameter of Tube
ABSTRACT

Shell-and-tube heat exchangers are the most common heat exchangers that can be found in several industrial applications. The reduction of the investment cost and the operation of this equipment it's one of main industrial designers and entrepreneurs aim. With the intention of reducing total costs of a shell-and-tube heat exchangers, as proposed by Caputo et al. (2008), employed in this present study the optimization technique called Differential Evolution (DE), which basically consists in a calculation mechanism, supported on operators of "crossing" and "mutation" differential, through mathematical and heuristics arguments that indicate your adequacy for function optimization. This study is defined as a mono-objective optimization problem and the total cost of a shell-and-tube heat exchanger is the objective function. To this, it was taken as a design variable intern diameter tube, the outer diameter of the shell and the spacing between baffles or deflectors. The results reached in this work were compared with the same problem when used GA (Genetics Algorithms), PSO (Particle Swarm Optimization), QPSO (Quantum Particle Swarm Optimization) and QPSOZ (Quantum Particle Swarm Optimization by Zaslavskii). Regarding the literature, the capital investment in the heat exchange reduces corresponding in $15.2 \%$ and consequently the depreciation charge of the equipment decrease approximately $12.5 \%$. In general, the total cost of the shell-and-tube heat exchange in analysis, presented a reduction of $15 \%$, showing the potential of applied method in this study, the technique DE.

Keywords: cost optimization, shell-and-tube heat exchanger, differential evolution

$\begin{array}{rllr} & \mathrm{D}_{\mathrm{s}} & \text { Internal Diameter of Shell } & \mathrm{m} \\ & \mathrm{F}_{\mathrm{a}} & \text { Correction Factor } & {[-]} \\ € & \mathrm{f}_{\mathrm{s}} & \text { Friction Coefficient on Shell Side } & {[-]} \\ € / \mathrm{m}^{2} & \mathrm{f}_{\mathrm{t}} & \text { Friction Coefficient on Tube Side } & {[-]} \\ {[-]} & \mathrm{H} & \text { Operation Annual Time } & \mathrm{h} / \mathrm{Year} \\ \mathrm{m}^{2} & \mathrm{~h}_{\mathrm{s}} & \text { Convection Coef. on Shell Side } & \mathrm{W} / \mathrm{m}^{2} \mathrm{~K} \\ \mathrm{~m}^{2} & \mathrm{~h}_{\mathrm{t}} & \text { Convection Coef. on Tube Side } & \mathrm{W} / \mathrm{m}^{2} \mathrm{~K} \\ \mathrm{~m} & \mathrm{i} & \text { Depreciation Annual Rate } & \% \\ {[-]} & \mathrm{k} & \text { Thermal Conductivity } & \mathrm{W} / \mathrm{mK} \\ € / \mathrm{kWh} & \mathrm{L} & \text { Length of Tubes } & \mathrm{m} \\ € & \dot{\mathrm{m}}_{\mathrm{s}} & \text { Mass Flow on Shell Side } & \mathrm{kg} / \mathrm{s} \\ € & \dot{\mathrm{m}}_{\mathrm{t}} & \text { Mass Flow on Tube Side } & \mathrm{kg} / \mathrm{s} \\ € & \mathrm{n} & \text { Number of Pass on Tubes } & {[-]} \\ \mathrm{J} / \mathrm{kgK} & \mathrm{n}_{1} & \text { Numeric Constant } & {[-]} \\ € & \mathrm{n}_{\mathrm{y}} & \text { Equipment Life } & \text { Years } \\ \mathrm{m} & \mathrm{N}_{\mathrm{t}} & \text { Number of Tubes } & {[-]} \\ \mathrm{m} & \mathrm{P} & \text { Power Pumping } & \mathrm{W} \\ \mathrm{m} & \mathrm{Pr}_{\mathrm{s}} & \text { Prandtl Number on Shell Side } & {[-]}\end{array}$




\begin{tabular}{|c|c|}
\hline $\operatorname{Pr}_{t}$ & Prandtl Number on Tube Side \\
\hline Q & Amount of Heat \\
\hline $\operatorname{Re}_{\mathrm{s}}$ & Reynolds Number on Shell Side \\
\hline $\operatorname{Re}_{t}$ & Reynolds Number on Tube Side \\
\hline $\mathrm{R}_{\mathrm{fs}}$ & Cond. Thermal Resist. on Shell \\
\hline $\mathrm{R}_{\mathrm{ft}}$ & Cond. Thermal Resist. on Tube \\
\hline $\mathrm{S}_{\mathrm{t}}$ & Distance Between the Tubes \\
\hline $\mathrm{T}_{\mathrm{is}}$ & Fluid Temp. Internal on Shell \\
\hline $\mathrm{T}_{\text {os }}$ & Fluid Temp. External on Shell \\
\hline $\mathrm{T}_{\mathrm{it}}$ & Fluid Temp. Internal on Tube \\
\hline $\mathrm{T}_{\mathrm{ot}}$ & Fluid Temp. External on Tube \\
\hline $\mathrm{U}$ & Heat Transfer Global Coefficient \\
\hline $\mathrm{V}_{\mathrm{s}}$ & Fluid Velocity on Shell Side \\
\hline $\mathrm{V}_{\mathrm{t}}$ & Fluid Velocity on Tube Side \\
\hline$\Delta \mathrm{P}_{\mathrm{s}}$ & Pressure Drop on Shell Side \\
\hline$\Delta \mathrm{P}_{\mathrm{t}}$ & Pressure Drop on Tube Side \\
\hline$\Delta \mathrm{T}_{\mathrm{ML}}$ & Temp Difference Logarithm Mean \\
\hline iter $_{\max }$ & Maximum Number of Generations \\
\hline $\mathrm{DE}$ & Differential Evolution \\
\hline GA & Genetic Algorithms \\
\hline PSO & Particle Swarm Optimization \\
\hline QPSO & Quantum Particle Swarm Optimization \\
\hline QPSOZ & Quantum Part. Swarm Opt. - Zaslavski \\
\hline $\mathrm{F}$ & Mutation Factor \\
\hline CR & Crossover Probability \\
\hline$N$ & Individuals Number of the Population \\
\hline
\end{tabular}

\section{Greek Symbols}

$\begin{array}{ll}\mu & \text { Dynamic Viscosity } \\ \rho & \text { Density } \\ \eta & \text { Efficiency of Operation } \\ \pi & \text { Numeric Constant }\end{array}$

\section{Subscripts}

$$
\begin{array}{ll}
\text { máx } & \text { Maximum } \\
\mathrm{s} & \text { Shell Side } \\
\mathrm{t} & \text { Tube Side } \\
\text { tot } & \text { Total }
\end{array}
$$

\section{INTRODUCTION}

Heat exchangers are, in general, equipments that realize a heat exchange process between two systems, hot fluid and cold fluid, according to the Thermodynamics Law and, therefore, provide the reuse of thermal energy from the hot fluids. Thus, to save energy, heat exchangers are important tools for the preservation of the environment and maintenance of the energy matrix. This equipment is used in several sectors of the engineering, for example, heaters, refrigerator, air conditioners, power generation plants, oil refineries, natural gas processing and treatment residual waters. There are few heat exchangers in which the fluids are in direct contact each other. In most of them, the heat transfer process occurs through of a separation surface where the heat is transferred from a fluid to other (Sekulic and Shah, 2003). Besides it, among the several types of exchangers, the shell-and-tube heat exchangers are applied in many situations and, therefore, maybe be the exchanger with higher application in industrial sector.

After a detailed investigation in the literature, it is possible to see the extensive use of numerical methods for solving several optimization problems in the scientific community. With the focus on heat exchangers, it was found that, in general, the most of studies include the use of objective functions to optimize consumption energy and their geometric characteristics, in addition to operating and investment costs. One of the first studies in the literature about the subject is that of Sun et al. (1993). The authors proposed an energy optimization model for shell-andtube heat exchangers where the objective function was the total generation entropy rate of the system. It were realized experimental tests in shell-and-tube heat exchangers showing that the values obtained were in accordance with the mathematical model used, confirming the effectiveness of the optimization process. Muralikrishna and Shenoy (2000) proposed a methodology, based on the Kern method and in optimization deterministic techniques to obtain the best geometric and cost conditions for shell-and-tube heat exchangers, besides to evaluate the distribution of the pressure drop these equipment. Selbas et al. (2006) applied Genetic Algorithms (GA) to find the optimal settings related to the diameter of tubes, number of passes and dimensions of the shell. Also, they used the Logarithm Mean Temperature Difference (LMTD) to determine the heat transfer area of shell-and-tube heat exchanger. Babu and Munawar (2007) were one of the first authors to use Differential Evolution (DE) techniques (Price and Storn, 1997) for solver the optimal configurations of shell-and-tube heat exchangers. In addition, for comparison of results, the authors also applied GA and found that the DE presented a calculus speed faster when compared with GA. Caputo et al. (2008) also used GA to minimize the total cost of a shell-and-tube heat exchanger, including the equipment investment cost and energy costs related to functioning. Patel and Rao (2010) studied the same problem analyzed by Caputo et al. (2008), but using the Particle Swarm Optimization (PSO) technique. When they applied this technique and analyze the results, the authors found a reduction in both the costs, of investment and of operation. Among the four cases of studies analyzed by Patel and Rao (2010), the reduction in investment capital ranged between 2.9 and $6.6 \%$ and in operation costs, the variation was between 14.1 and 15.9\%. In 2012, 
Mariani et al. (2012) continued the work of Caputo et al. (2008) and Rao and Patel (2010). In this study, the authors used the Quantum Particle Swarm Optimization (QPSO) and Quantum Particle Swarm Optimization combined with Zaslavskii Chaotic Map (QPSOZ) and the results were, again, satisfactory. In general, the costs presented a significant reduction compared with others studies. This paper proposes the study and application of DE optimization method to optimize the shell-and-tube heat exchanger investigated by Caputo et al. (2008), Patel and Rao (2010) and Mariani et al. (2012).

\section{DIFFERENTIAL EVOLUTION}

The Differential Evolution (DE) algorithm, developed by Price and Storn (1997), is an efficient stochastic optimization algorithm that has been highlighted in the field of nonlinear optimization of continuous variables. It is based on a calculus mechanism, sustained by the operators "crossover" and "mutation" differential, through mathematical and heuristic arguments that indicate their suitability for the optimization of functions. For be a method based in population, the DE maintains a set of solutions which evolves through a process by generating new solutions and possible alternatives to the population for new solutions that may be better or more promising. The generation of new solutions is made by a mutation operator that realize a linear combination of the three solutions of the population and a crossover operator blending the vector coordinates generated by the mutation operation and a fourth solution of the population (crossover selection). The later solution will compete with the new solution generated by the permanence in the population. If the new solution obtained is better than the crossover solution by according some pre-established selection criteria, then the crossover solution will be replaced by new generated solution (Melo et al., 2008).

\section{Differential Evolution Operators}

Consider a solution possible population for a problem, represented by $\mathrm{X}_{\mathrm{t}}=\left\{\mathrm{X}_{\mathrm{t}, \mathrm{i}} ; \mathrm{i}=1,2,3, . ., \mathrm{N}\right\}$, where $t$ is the index of the current generation, and $i$ us the index of an individual in this population. Each individual in the current population can be represented by the following column vector:

$$
\mathrm{X}_{\mathrm{t}, \mathrm{i}}=\left[\begin{array}{c}
\mathrm{X}_{\mathrm{t}, \mathrm{i}, 1} \\
\vdots \\
\mathrm{X}_{\mathrm{t}, \mathrm{i}, \mathrm{n}}
\end{array}\right]
$$

thus the third index represents a problem among the $n$ variables to be optimized.

The search mechanism of DE algorithm uses differential vectors created from the population vectors pairs. Two individuals are randomly selected from the current population, creating a difference vector, that is, the difference between these two individuals. This vector is added to a third individual, also selected at random, producing a new mutant solution. The new mutant solution is, therefore, the result of a modification in some individuals in the population. Mathematically, it is defined as:

$$
\mathrm{v}_{\mathrm{t}, \mathrm{i}}=\mathrm{x}_{\mathrm{t}, \mathrm{r} 1 \mathrm{1}}+\mathrm{F}\left(\mathrm{x}_{\mathrm{t}, \mathrm{r} 2}-\mathrm{x}_{\mathrm{t}, \mathrm{r} 3}\right)
$$

with $r_{1}, r_{2}, r_{3} \in\{1,2,3, \ldots, N\}$. Besides it, $v_{t, i}$ is the $i$-th mutant solution and $\mathrm{F}$ is a scale factor applied to the differential vector and DE algorithm parameter, called mutation factor. The vector $\mathrm{x}_{\mathrm{t}, \mathrm{r} 1}$ is called vector base.

In this procedure, it is possible to obtain a mutant population $\mathrm{V}_{\mathrm{t}}=\left\{\mathrm{v}_{\mathrm{t}, \mathrm{i}} ; \mathrm{i}=1,2,3, \ldots, \mathrm{N}\right\}$, and after that, the individuals of the current population $\mathrm{X}_{\mathrm{t}}$ are discretely recombined with probability $\mathrm{CR}$ with the mutant population individuals, producing a progeny or test solutions population, $\mathrm{U}_{\mathrm{t}}$.

$$
u_{t, i, j}=\left\{\begin{array}{l}
v_{t, i, j} \text { if } U_{[0,1]} \leq C R \\
x_{t, i, j} \text { if Otherwise }
\end{array}\right.
$$

where $\mathrm{U}_{[0,1]}$ represents a random sampling of a variable with uniform distribution in the interval [0,1]. The CR parameter controls the fraction of $\mathrm{u}_{\mathrm{t}, \mathrm{i}}$ will be copied from the mutant vector $\mathrm{v}_{\mathrm{t}, \mathrm{i}}$. The DE procedure is illustrated in Fig. (1).

Finally, the objective function value is evaluated in $u_{t, i}$ and each test solution is compared with the corresponding in the current population $\mathrm{x}_{\mathrm{t}, \mathrm{i}}$. If the test solution is better than the current population $x_{t, i}$, the current solution is changed and its place becomes occupied by $\mathrm{u}_{\mathrm{t}, \mathrm{i}}$. Otherwise, the test solution is discarded and the current solution survives, remaining next generation of the population, represented by $\mathrm{X}_{\mathrm{t}+1}$ The iterative procedure is repeated until a sopping criteria (or convergence) is satisfied. The criteria for survival of a solution, for an objective function minimization problem, can be described by:

$$
x_{t+1, i}=\left\{\begin{array}{l}
u_{t, i} \text { if } f\left(u_{t, i}\right) \leq f\left(x_{t, i}\right) \\
x_{t, i} \text { if } \quad \text { Otherwise }
\end{array}\right.
$$

\section{Strategies and Parameters - Differential Evolution}

The DE strategies vary with the type of individual it will be modified in the vector formation, with the number of individuals considered for the perturbation and the crossover type to be used. It is can be written as $\mathrm{DE}-\alpha-\beta-\gamma$ (Rocha and Saramago, 2011), where $\alpha$ specifies the vector it will 
be perturbed and may be "rand” (random population vector) or "best" (population lower cost vector), $\beta$ determines the number of weighted differences used to perturbed $\alpha$ and $\gamma$ denotes the type of crossover, may be “exp” (exponential) or "bin” (binomial). Therefore, it is convenient to analyze which strategies return the best solution to the problem. For the solution of this study, the best strategy to be used is "DE/rand/1/bin", also known as "Strategy 7".

The DE is a stochastic optimization method that uses three parameters that need to be adjusted in their algorithm. They are: population size $(\mathrm{N})$, mutation factor (F) and crossover probability (CR). Since the creation of this method, a lot of studies have been realized to verify the suitability of these parameters. According Storn and Price (1997), most often $\mathrm{CR} \in[0,1]$, but if, however, the convergence is not satisfied, it is better to use a range between 0.8 and 1.0. In many application, the appropriate population size is $N=10$, where $D$ is the number of design variables. Besides it, the mutation factor is usually defined in $\mathrm{F} \in[0.5,1.0]$. The $\mathrm{DE}$ parameters used in this study were $\mathrm{F}=0.5, \mathrm{CR}=0.8, \mathrm{~N}=30$ and iter $_{\text {máx }}=1000$, where iter $_{\text {máx }}$ is the maximum number of generations.

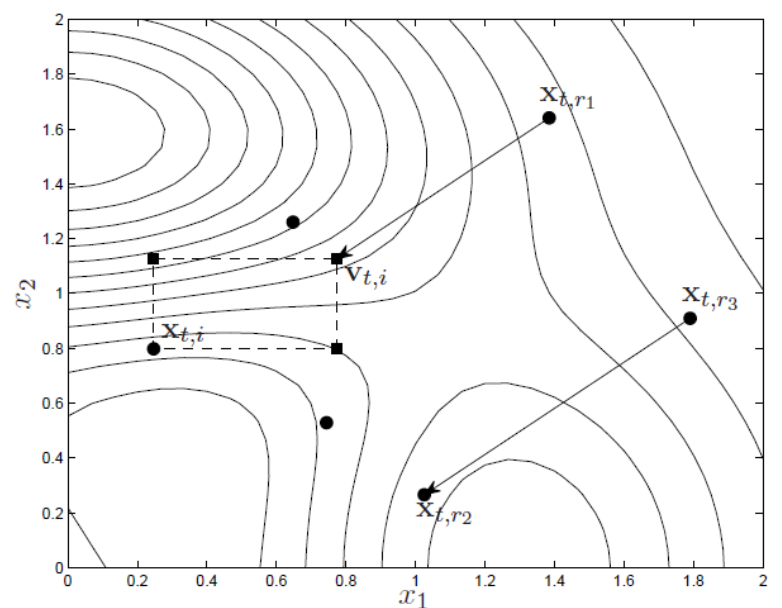

Figure 1. A New Mutant Solution Procedure. Source: Rocha and Saramago, 2011.

\section{MATHEMATICAL MODELING}

The heat transfer rate, Q [W], for a shell-andtube heat exchanger can be defined as (Caputo et al., 2008):

$$
\mathrm{dQ}=\mathrm{U} \cdot \mathrm{F}_{\mathrm{a}} \cdot \mathrm{dA} \cdot \Delta \mathrm{T}_{\mathrm{ML}}
$$

However, the exact determination of the heat transfer area, A $\left[\mathrm{m}^{2}\right]$, is a problem. To calculate this area, to promote the heat exchange between the fluids in a time interval, it is necessary to integrate the Eq. (5) along the heat transfer total rate of the heat exchanger, as:

$$
\mathrm{A}=\int_{0}^{\mathrm{Q}} \frac{\mathrm{dQ}}{\mathrm{U} \cdot \mathrm{F}_{\mathrm{a}} \cdot \Delta \mathrm{T}_{\mathrm{ML}}}=\frac{\mathrm{Q}}{\mathrm{U} \cdot \mathrm{F}_{\mathrm{a}} \cdot \Delta \mathrm{T}_{\mathrm{ML}}}
$$

where $\mathrm{U}\left[\mathrm{W} / \mathrm{m}^{2} \mathrm{~K}\right]$ is the heat transfer total coefficient, $\mathrm{F}_{\mathrm{a}}$ is a factor of temperature difference correction for non-concentric tubes and $\Delta \mathrm{T}_{\mathrm{ML}}$ is the temperature difference logarithm mean, described by:

$$
\Delta \mathrm{T}_{\mathrm{ML}}=\frac{\left(\mathrm{T}_{\mathrm{is}}-\mathrm{T}_{\mathrm{ot}}\right)-\left(\mathrm{T}_{\mathrm{os}}-\mathrm{T}_{\mathrm{it}}\right)}{\ln \left(\frac{\mathrm{T}_{\mathrm{is}}-\mathrm{T}_{\mathrm{ot}}}{\mathrm{T}_{\mathrm{os}}-\mathrm{T}_{\mathrm{it}}}\right)}
$$

where $T_{i s}$ and $T_{i t}$ are the fluid temperatures in the intern side of the shell and the tube and $T_{\text {os }}$ and $T_{o t}$ are the fluid temperatures in the extern side of the shell and the tube, respectively.

The correction factor $F_{a}$ can be calculated using an empirical correlation as a function of the fluid temperatures on heat exchanger, proposed by Fraas (1989).

$$
F_{a}=\frac{\sqrt{\mathrm{R}^{2}+1}}{\mathrm{R}-1} \cdot \frac{\ln \left(\frac{1-\mathrm{P}}{1-\mathrm{P} \cdot \mathrm{R}}\right)}{\ln \left(\frac{2-\mathrm{P} \cdot \mathrm{R}-\mathrm{P}+\mathrm{P} \cdot \sqrt{\mathrm{R}^{2}+1}}{2-\mathrm{P} \cdot \mathrm{R}-\mathrm{P}-\mathrm{P} \cdot \sqrt{\mathrm{R}^{2}+1}}\right)}
$$

where:

$$
\begin{array}{r}
\mathrm{P}=\frac{\mathrm{T}_{\mathrm{ot}}-\mathrm{T}_{\mathrm{it}}}{\mathrm{T}_{\mathrm{is}}-\mathrm{T}_{\mathrm{it}}} \\
\mathrm{R}=\frac{\mathrm{T}_{\mathrm{is}}-\mathrm{T}_{\mathrm{os}}}{\mathrm{T}_{\mathrm{ot}}-\mathrm{T}_{\mathrm{it}}}
\end{array}
$$

For a case when there is a sensible heat transfer in the heat exchanger, the heat transfer rate is defined as:

$$
\mathrm{Q}=\dot{\mathrm{m}}_{\mathrm{s}} \cdot \mathrm{c}_{\mathrm{p}, \mathrm{s}} \cdot\left(\mathrm{T}_{\mathrm{is}}-\mathrm{T}_{\mathrm{os}}\right)=\dot{\mathrm{m}}_{\mathrm{t}} \cdot \mathrm{c}_{\mathrm{p}, \mathrm{t}} \cdot\left(\mathrm{T}_{\mathrm{os}}-\mathrm{T}_{\mathrm{it}}\right)
$$

where $\dot{\mathrm{m}}_{\mathrm{s}}$ and $\dot{\mathrm{m}}_{\mathrm{t}}$ are the mass flow rates of the fluid in the shell and tube side $c_{p, s}$ and $c_{p, t}$ are the specific heat of the fluid in the shell and tube side, respectively.

In general, the shell-and-tube heat exchanger project depends from an analysis on both sides of the equipment, it is necessary to analyze the shell and the tube individually. In this study, all equations that are described with the subscript "t" refers to the tube side and that are described with subscript "s" are related to the shell tube.

The heat transfer global coefficient $U$ depends of the convection heat transfer coefficient, $h$, and of the conduction thermal resistance, $\mathrm{R}_{\mathrm{f}}$, on the shell and the 
tube, calculated by:

$$
\mathrm{U}=\frac{1}{\frac{1}{h_{s}}+R_{s}+\left(\frac{d_{0}}{d_{i}}\right) \cdot\left(R f_{t}+\frac{1}{h_{t}}\right)}
$$

where $\mathrm{d}_{0}$ and $\mathrm{d}_{\mathrm{i}}$ are the diameters, external and internal, of the tube, respectively. Thus, in this work $\mathrm{d}_{\mathrm{i}}=0.84 \cdot \mathrm{d}_{0}$. Importantly that $\mathrm{d}_{0}$ is one of the design variable of this study and its dimensions are restricted to the range $0.010 \leq \mathrm{d}_{0} \leq 0.032$.

Heat transfer coefficient in the shell side $\left(\mathrm{h}_{\mathrm{s}}\right)$ proposed by Kern (1950), can be calculated as:

$$
\mathrm{h}_{\mathrm{s}}=0.36 \cdot \frac{\mathrm{k}_{\mathrm{s}}}{\mathrm{d}_{\mathrm{e}}} \cdot \operatorname{Re}_{\mathrm{s}}^{0.55} \cdot \operatorname{Pr}_{\mathrm{s}}^{1 / 3} \cdot\left(\frac{\mu_{\mathrm{s}}}{\mu_{\mathrm{ws}}}\right)^{0.14}
$$

where $\mu_{\mathrm{s}}$ and $\mu_{\mathrm{ws}}$ are the dynamic viscosities of the fluid present in the shell and in its wall, respectively, $\mathrm{k}_{\mathrm{s}}$ is the thermal conductivity of the shell material, $\mathrm{Pr}_{\mathrm{s}}$ and $\mathrm{Re}_{\mathrm{s}}$ refers to Prandtl and Reynolds number on the shell side and $d_{e}$ is the equivalent diameter of the shell side.

The Prandtl and Reynolds number can be calculated, respectively, by:

$$
\begin{aligned}
& \operatorname{Pr}_{\mathrm{s}}=\frac{\mu_{\mathrm{s}} \cdot \mathrm{c}_{\mathrm{p}, \mathrm{s}}}{\mathrm{k}_{\mathrm{s}}} \\
& \operatorname{Re}_{\mathrm{s}}=\frac{\dot{\mathrm{m}}_{\mathrm{s}} \cdot \mathrm{d}_{\mathrm{e}}}{\mathrm{A}_{\mathrm{S}} \cdot \mu_{\mathrm{s}}}
\end{aligned}
$$

where $A_{S}$ is the cross-sectional area of the shell side and normal to the flow direction, calculated by:

$$
A_{S}=D_{s} \cdot B \cdot\left(1-\frac{d_{0}}{S_{t}}\right)
$$

where $D_{s}$ and $B$ are more two optimization variables of this study and refer, respectively to the shell internal diameter and the spacing of heat exchanger deflectors. The optimization constraints is in the interval $0.15 \leq \mathrm{D}_{\mathrm{s}} \leq 1.20$ and $0.20 \leq \mathrm{B} \leq 0.45$.

The equivalent diameter on the shell side, $\mathrm{d}_{\mathrm{e}}$, utilized in Eq. (13), is calculated by:

$$
\mathrm{d}_{\mathrm{e}}=\frac{4\left(0.43 \cdot \mathrm{S}_{\mathrm{t}}{ }^{2}-0.5 \cdot \pi \cdot \frac{\mathrm{d}_{0}{ }^{2}}{4}\right)}{0.5 \cdot \pi \cdot \mathrm{d}_{0}}
$$

The relation between $d_{0}$ and $S_{t}$, can be seen in Fig. (2), $S_{t}=1.25 \cdot d_{0}$.

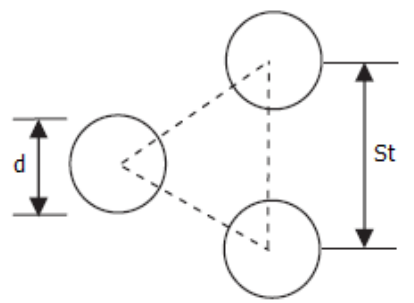

Figure 2. Triangular Configuration of the Tubes on Heat Exchanger. Source: Caputo et al. (2008).

The heat exchanger coefficient on the tube side, $h_{t}$, can be calculated from the following empirical correlations:

If $\operatorname{Re}_{\mathrm{t}}<10000$ :

$$
h_{t}=\frac{k_{t}}{d_{i}} \cdot\left[\frac{\frac{f_{t}}{2} \cdot\left(R_{t}-1000\right) \cdot P r_{t}}{1+12.7 \cdot \sqrt{\frac{f_{t}}{2}} \cdot\left(\operatorname{Pr}_{t}^{2 / 3}-1\right)}\right]
$$

Otherwise:

$$
\mathrm{h}_{\mathrm{t}}=0.027 \cdot \frac{\mathrm{k}_{\mathrm{t}}}{\mathrm{d}_{\mathrm{i}}} \cdot \mathrm{Re}_{\mathrm{t}}^{0.8} \cdot \operatorname{Pr}_{\mathrm{t}}^{1 / 3} \cdot\left(\frac{\mu_{\mathrm{t}}}{\mu_{\mathrm{wt}}}\right)^{0.14}
$$

The above equations are dependent of the Prandtl number, $\mathrm{Pr}_{t}$, Reynolds number, $\mathrm{Re}_{t}$, and Darcy friction factor, $f_{t}$, both for the tube side.

$$
\begin{gathered}
\operatorname{Pr}_{\mathrm{t}}=\mu_{\mathrm{t}} \cdot \mathrm{c}_{\mathrm{p}, \mathrm{t}} \cdot \mathrm{k}_{\mathrm{t}}^{-1} \\
\mathrm{f}_{\mathrm{t}}=\left(1.82 \cdot \log \mathrm{Re}_{\mathrm{t}}-1.64\right)^{-2} \\
\operatorname{Re}_{\mathrm{t}}=\rho_{\mathrm{t}} \cdot \mathrm{V}_{\mathrm{t}} \cdot \mathrm{d}_{\mathrm{i}} \cdot \mu_{\mathrm{t}}^{-1}
\end{gathered}
$$

where the fluid flow velocity in the tube side $\left(V_{t}\right)$ is given by:

$$
\mathrm{V}_{\mathrm{t}}=\frac{\dot{\mathrm{m}}_{\mathrm{t}}}{\pi / 4 \cdot \mathrm{d}_{\mathrm{i}}^{2} \cdot \rho_{\mathrm{t}}} \cdot\left(\frac{\mathrm{n}}{\mathrm{N}_{\mathrm{t}}}\right)
$$

where $\mathrm{n}$ is the number of steps in the tube side and $N_{t}$ is the number of tubes, calculated by:

$$
\mathrm{N}_{\mathrm{t}}=\mathrm{C} \cdot\left(\frac{\mathrm{D}_{\mathrm{s}}}{\mathrm{d}_{0}}\right)^{\mathrm{n}_{1}}
$$


For a heat exchanger with 2 passes on tube side, as in this study, $\mathrm{C}=0.249$ and $\mathrm{n}_{1}=2.207$.

Based on the calculus of the heat transfer total area, $\mathrm{A}$, is possible to determine the length of the heat exchanger tubes, through:

$$
\mathrm{L}=\frac{\mathrm{A}}{\pi \cdot \mathrm{d}_{0} \cdot \mathrm{N}_{\mathrm{t}}}
$$

\section{Pressure Drop}

In shell-and-tube heat exchanger, the total pressure drop in the tube size is calculated by adding the distributed pressure drop along the length of tubes with the located pressure drop. With this, the total pressure drop on the tubes side, $\Delta \mathrm{P}_{\mathrm{t}}$, can be defined according to:

$$
\Delta P_{t}=\frac{\rho_{t} \cdot V_{t}^{2}}{2} \cdot\left(\frac{L}{d_{i}} \cdot f_{t}+p\right) \cdot n
$$

where $\mathrm{p}$ is the drop coefficient. In this study, was adopted $\mathrm{p}=4$, as proposed in the study of Kern (1950).

The total pressure drop in the shell side is defined as:

$$
\Delta \mathrm{P}_{\mathrm{s}}=\mathrm{f}_{\mathrm{s}} \cdot\left(\frac{\rho_{\mathrm{s}} \cdot \mathrm{V}_{\mathrm{s}}^{2}}{2}\right) \cdot \frac{\mathrm{L}}{\mathrm{B}} \cdot \frac{\mathrm{D}_{\mathrm{s}}}{\mathrm{d}_{\mathrm{e}}}
$$

where $f_{s}$ is the friction factor on the shell side, calculated by:

$$
\mathrm{f}_{\mathrm{s}}=2 \cdot \mathrm{b}_{0} \cdot \operatorname{Re}_{\mathrm{s}}{ }^{-0.15}
$$

and $\mathrm{b}_{0}=0.72$, valid to $\operatorname{Re}_{\mathrm{s}}<40000$, according to a numerical study developed by Peters and Timmerhaus (1991).

\section{Objective Function}

The total cost of the heat exchanger, $C_{\text {tot }}$, is the objective functions of this study. This cost includes the capital investment, $C_{i}$, the cost of energy, $C_{e}$, the annual operating cost of the equipment, $\mathrm{C}_{0}$, and the total cost of operating depreciation, $\mathrm{C}_{\text {od }}$ (Caputo et al., 2008).

$$
\mathrm{C}_{\text {tot }}=\mathrm{C}_{\mathrm{i}}+\mathrm{C}_{\mathrm{od}}
$$

Adopting the Hall's correlation (Taal et al., 2003), the capital investment, $C_{i}$, is calculated according to the heat transfer total area, $\mathrm{A}$, given by $\mathrm{C}_{\mathrm{i}}=\mathrm{a}_{1}+\mathrm{a}_{2} \cdot \mathrm{A}^{\mathrm{a}}$, where $\mathrm{a}_{1}, \mathrm{a}_{2}$ and $\mathrm{a}_{3}$ are numeric constants related to the manufacturing material of the heat exchanger. In this study, was selected that the tubes and the shell are fabricated of stainless steel and, because of it, $\mathrm{a}_{1}=8000, \mathrm{a}_{2}=259.2$ and $\mathrm{a}_{3}=0.91$. The total cost of operating depreciation is calculated by:

$$
C_{\text {od }}=\sum_{j=1}^{n_{y}} \frac{C_{o}}{(1+i)^{j}}
$$

where $\mathrm{n}_{\mathrm{y}}$ represents the equipment life in years. In this study, was adopted $\mathrm{n}_{\mathrm{y}}=10 \mathrm{years}$.

The operating cost, $\mathrm{C}_{\mathrm{o}}$, is calculated by:

$$
\mathrm{C}_{\mathrm{o}}=\mathrm{P}_{1} \cdot \mathrm{C}_{\mathrm{e}} \cdot \mathrm{H}
$$

where $\mathrm{C}_{\mathrm{e}}=0.12 € / \mathrm{kWh}=0.00012$, the annual time of equipment operating $\mathrm{H}=7000 \mathrm{~h} /$ year and the annual depreciation rate $\mathrm{i}=10 \%=0.10$.

The term $\mathrm{P}_{1}$ represents the power pumping on heat exchanger, with $80 \%$ efficiency $(\eta=80 \%=0.8$ ) and can be calculated by:

$$
\mathrm{P}_{1}=\frac{1}{\eta} \cdot\left(\frac{\dot{\mathrm{m}}_{\mathrm{t}}}{\rho_{\mathrm{t}}} \cdot \Delta \mathrm{P}_{\mathrm{t}}+\frac{\dot{\mathrm{m}}_{\mathrm{s}}}{\rho_{\mathrm{s}}} \cdot \Delta \mathrm{P}_{\mathrm{s}}\right)
$$

The problem to be studied has some construction and operational important characteristics to the development of the study (Caputo el al., 2008). These data are detailed below.

- $\quad$ Fluid on shell side: Methanol

- Fluid on tube side: SeaWater

- Number of pass in the shell side: 01

- $\quad$ Number of passes in the tubes side (n): 02

Finally, the thermophysical properties of the fluids that will go through the heat exchanger are show in Tab. (1).

Table 1. Thermophysical Properties of the Fluids on Shell and Tube Side.

\begin{tabular}{c|c|c}
\cline { 2 - 3 } & $\begin{array}{c}\text { Shell } \\
\text { Methanol }\end{array}$ & $\begin{array}{c}\text { Tubes } \\
\text { SeaWater }\end{array}$ \\
\hline Flow Vel $[\mathrm{kg} / \mathrm{s}]$ & 27.80 & 68.90 \\
\hline $\mathrm{T}_{\mathrm{i}}\left({ }^{\circ} \mathrm{C}\right)$ & 95 & 25 \\
\hline $\mathrm{T}_{\mathrm{o}}\left({ }^{\circ} \mathrm{C}\right)$ & 40 & 40 \\
\hline$\rho\left(\mathrm{kg} / \mathrm{m}^{3}\right)$ & 750 & 995 \\
\hline $\mathrm{C}_{\mathrm{p}}(\mathrm{J} / \mathrm{kgK})$ & 2840 & 4200 \\
\hline$\mu(\mathrm{Pa} . \mathrm{s})$ & 0.00034 & 0.00080 \\
\hline$\mu_{\mathrm{w}}(\mathrm{Pa} . \mathrm{s})$ & 0.00038 & 0.00052 \\
\hline $\mathrm{k}(\mathrm{W} / \mathrm{mK})$ & 0.19 & 0.59 \\
\hline $\mathrm{Rf}\left(\mathrm{m}^{2} \mathrm{~K} / \mathrm{W}\right)$ & 0.00033 & 0.00020 \\
\hline
\end{tabular}

Source: Caputo et al. (2008). 


\section{RESULTS AND DISCUSSION}

The main objective of this study is to verify the effectiveness of DE compared to another optimization applied in the optimal solution of a shell-and-tube heat exchanger, with two passes in the tubes and one pass in the shell, as discussed above in the literature by
Caputo et al. (2008) using GA, Patel and Rao (2010) using the PSO method and Mariani et al. (2012) using QPSO and QPSOZ. The Tab. (2) shows the values obtained with the DE and compares with other optimization approaches. All analyzes will be compared to the numerical values of Caputo et al. (2008).

Table 2. Optimal Design of a Shell-and-Tube Heat Exchanger using different Optimization Approaches.

\begin{tabular}{|c|c|c|c|c|c|c|}
\hline & & GA (1) & PSO (2) & QPSO (3) & QPSOZ (4) & DE (5) \\
\hline $\mathrm{d}_{0}$ & $\mathrm{~m}$ & 0.0160 & 0.0150 & 0.0150 & 0.0150 & 0.0100 \\
\hline $\mathrm{B}$ & $\mathrm{m}$ & 0.5000 & 0.4240 & 0.3850 & 0.3830 & 0.4500 \\
\hline $\mathrm{D}_{\mathrm{s}}$ & $\mathrm{m}$ & 0.8300 & 0.8100 & 0.8290 & 0.8290 & 0.8430 \\
\hline $\mathrm{N}_{\mathrm{t}}$ & - & 1.517 & 1658 & 1745 & 1745 & 4431 \\
\hline $\mathrm{V}_{\mathrm{t}}$ & $\mathrm{m} / \mathrm{s}$ & 0.64 & 0.67 & 0.64 & 0.64 & 0.56 \\
\hline $\mathrm{Re}_{\mathrm{t}}$ & - & 10759 & 10503 & 9979 & 9979 & 5895 \\
\hline $\mathrm{f}_{\mathrm{t}}$ & - & 0.031 & 0.031 & 0.032 & 0.032 & 0.037 \\
\hline $\mathrm{d}_{\mathrm{e}}$ & $\mathrm{m}$ & 0.011 & 0.011 & 0.011 & 0.011 & 0.011 \\
\hline $\mathrm{Pr}_{\mathrm{s}}$ & - & 5.1 & 5.1 & 5.1 & 5.1 & 5.1 \\
\hline $\operatorname{Re}_{\mathrm{S}}$ & - & 11219 & 12709 & 13676 & 13747 & 7671 \\
\hline $\mathrm{h}_{\mathrm{s}}$ & $\mathrm{W} / \mathrm{m}^{2} \mathrm{~K}$ & 1716 & 1960 & 2041 & 2046 & 2227 \\
\hline $\mathrm{h}_{\mathrm{t}}$ & $\mathrm{W} / \mathrm{m}^{2} \mathrm{~K}$ & 3779 & 3954 & 8389 & 8389 & 7530 \\
\hline $\mathrm{U}$ & $\mathrm{W} / \mathrm{m}^{2} \mathrm{~K}$ & 682 & 724 & 833 & 834 & 850 \\
\hline $\mathrm{V}_{\mathrm{s}}$ & $\mathrm{m} / \mathrm{s}$ & 0.45 & 0.54 & 0.58 & 0.58 & 0.49 \\
\hline $\mathrm{A}$ & $\mathrm{m}^{2}$ & 254.6 & 239.6 & 208.4 & 208.2 & 204.1 \\
\hline $\mathrm{L}$ & $\mathrm{m}$ & 3340 & 3068 & 2536 & 2533 & 1467 \\
\hline $\mathrm{f}_{\mathrm{s}}$ & - & 0.36 & 0.35 & 0.35 & 0.34 & 0.38 \\
\hline$\Delta \mathrm{P}_{\mathrm{s}}$ & $\mathrm{Pa}$ & 12943 & 20915 & 22316 & 22623 & 13007 \\
\hline$\Delta \mathrm{P}_{\mathrm{t}}$ & $\mathrm{Pa}$ & 4804 & 5162 & 4168 & 4164 & 3296 \\
\hline $\mathrm{C}_{\mathrm{o}}$ & $€ /$ Year & 853 & 1189 & 1171 & 1183 & 746 \\
\hline $\mathrm{C}_{\text {od }}$ & $€$ & 5241 & 7308 & 7199 & 7271 & 4583 \\
\hline $\mathrm{C}_{\mathrm{i}}$ & $€$ & 48083 & 45923 & 41408 & 41373 & 40778 \\
\hline $\mathrm{C}_{\text {tot }}$ & $€$ & 53325 & 53231 & 48607 & 48644 & 45361 \\
\hline
\end{tabular}

Source: (1) Caputo et al. (2008) - (2) Patel and Rao (2010) - (3) and (4) Mariani et al. (2012) - (5) The Authors (2017).

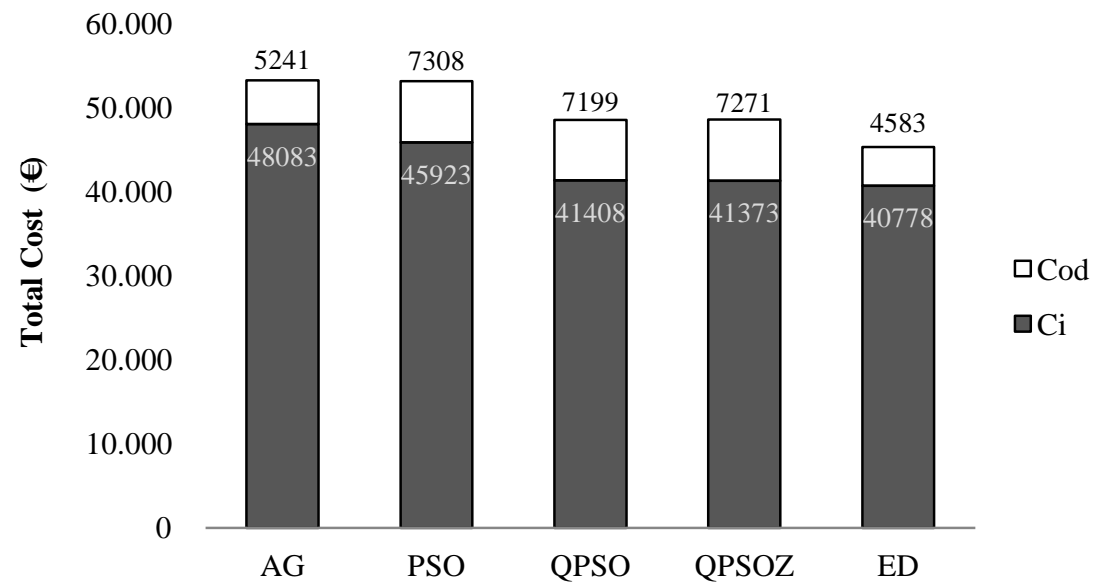

Figure 3. Comparative of the Total Cost for the Shell-and-Tube Exchanger. Source: The Authors (2017). 
According to the above values, it is possible to see that, when applying the DE, there is a reduction in heat transfer area of, approximately, 20\%, which do that the shell-and-tube heat exchanger presents also a reduction in the length of their tubes in $56.1 \%$, even with a significant increase in the number of tubes and decrease in their diameter. The capital investment in the heat exchanger reduced, approximately, $15.2 \%$ and, therefore, the total cost of depreciation decreases in $12.5 \%$. A general comparison of the total cost for this heat exchanger, according to different optimization approaches is present in Fig. (3).

\section{CONCLUSIONS}

A complete design of a heat exchanger is a complex work because of the many variables that are included in the thermal system development. However, several optimization advanced tools can be useful in order to design this equipment to identify the best and cheapest configuration of the heat exchanger for a particular applicability. In this study, the DE optimization method was applied to the problem proposed by Caputo et al. (2008), presenting satisfactory for the design of an optimal configuration of shell-and-tube heat exchanger from the economic point of view. When applied to problem in analyzes and compared to the results presented by Caputo et al. (2008) using GA, Patel and Rao (2010) using PSO and Mariani et al. (2012) using QPSO and QPSOZ, the DE showed the best results in terms of the objective function values. Regarding literature, the reduction in total cost of this shell-and-tube heat exchanger was, approximately, $15 \%$ in both approaches. The reduction in investment costs and equipment depreciation costs was, approximately, $15.2 \%$ and $12.5 \%$, respectively, when applied DE approach.

\section{ACKNOWLEDGMENT}

The authors of this study would like to thanks the Coordination for the Improvement of Higher Education Personnel (CAPES-MEC), the National Council for Scientific and Technological Development (CNPq-MEC), the Federal University of Paraná (UFPR) and the Pontifical Catholic University of Paraná (PUCPR).

\section{REFERENCES}

Babu, B. V., and Munawar, S. A., 2007, Differential Evolution Strategies for Optimal Design of Shell and Tube Heat Exchangers, Chemical Engineering and Processing, Vol. 62, pp. 3720-3739.

Caputo, A. C., Pelagagge, P. M., and Salini, P., 2008, Heat Exchanger Design based on Economic Optimization, Applied Thermal
Engineering, Vol. 28, pp. 1151-1159.

Gamperle, R., Muller, S. D., and Koumoutsakos, P. A., 2002, Parameter Study for Differential Evolution, International Conference on Advances in: International Systems and Fuzzy Systems, Evolutionary Computation.

Kern, D. Q., 1950, Process Heat Transfer, McGraw-Hill.

Mariani, V. C., Duck, A. R. K., Guerra, F. A., dos Santos Coelho, L., and Rao, R. V., 2012, A Chaotic Quantum-Behaved Particle Swarm Approach Applied to Optimization of Heat Exchangers, Applied Thermal Engineering, Vol. 42, pp. 119-128.

Muralikrishna, K., and Shenoy, U. V., 2000, Heat Exchanger Design Targets for Minimum Area and Cost, Chemical Engineering Research and Design, Vol. 78, No. 2, pp. 161-167.

Patel, V. K., and Rao, R. V., 2010, Design Optimization of Shell-and-Tube Heat Exchanger using Particle Swarm Optimization Technique, Applied Thermal Engineering, Vol. 30, No. 11, pp. 1417-1425.

Peters, M. S., Timmerhaus, K. D., West, R. E., Timmerhaus, K., and West, R., 1991, Plant Design and Economics for Chemical Engineers, Vol. 4. McGraw-Hill.

Price, K., and Storn, R., 1997, Differential Evolution, Dr. Dobb’s Journal, pp. 18-24.

Rocha, N. C., and Saramago, S. F. P., 2011, Estudo de Algumas Estratégias de Evolução Diferencial, in: Congresso de Matemática Aplicada e Computacional, CMAC Sudeste. (in Portuguese)

Selbaş, R., Kızılkan, Ö., and Reppich, M., 2006, A New Design Approach for Shell-And-Tube Heat Exchangers Using Genetic Algorithms from Economic Point of View, Chemical Engineering and Processing: Process Intensification, Vol. 45, No. 4, pp. 268-275.

Sinnott, R. K., and Towler, G., 2009, Chemical Engineering Design, SI Edition. Elsevier.

Shah, R. K., and Sekulic, D. P., 2003, Fundamentals of Heat Exchanger Design, John Wiley \& Sons.

Sun, S. Y., Lu, Y. D., and Yan, C. Q., 1993, Optimization in Calculation of Shell-Tube Heat Exchanger, International Communications in Heat and Mass Transfer, Vol. 20, No. 5, pp. 675-685. 